\title{
Endoscopic Cryotherapy of Lung and Bronchial Tumors: A Systematic Review
}

\author{
Seon-Heui Lee', Won-Jung Choi', Sook-Whan Sung ${ }^{2}$, Young-Kyoon Kim³ , Chi-Hong Kim ${ }^{4}$, Jae-II Zo ${ }^{5}$, \\ and Kwang-Joo Park ${ }^{6}$
}

\begin{abstract}
${ }^{1}$ National Evidence-Based Healthcare Collaborating Agency, Seoul; Departments of ${ }^{2}$ Thoracic and Cardiovascular Surgery and ${ }^{3}$ Internal Medicine, Seoul St. Mary's Hospital, The Catholic University of Korea School of Medicine, Seoul; ${ }^{4}$ Department of Internal Medicine, St. Vincent's Hospital, The Catholic University of Korea School of Medicine, Suwon; ${ }^{5}$ Center for Lung Cancer, Research Institute and Hospital, National Cancer Center, Goyang; ${ }^{6}$ Department of Pulmonary and Critical Care Medicine, Ajou University School of Medicine, Suwon, Korea
\end{abstract}

Background/Aims: We made a systematic review and evaluation of endoscopic cryotherapy of endobronchial tumors, investigating safety and efficacy.

Methods: Qualified studies regarding endoscopic cryotherapy of lung tumors were systemically evaluated using available databases according to predefined criteria.

Results: In total, 16 publications were included in the final assessment. A narrative synthesis was performed because a formal meta-analysis was not viable due to the lack of controlled studies and study heterogeneity. Overall success rates for significant recanalization of the obstruction were approximately $80 \%$, although they varied, depending on disease status in the patient population. Complications from the procedure developed in $0-11.1 \%$ of cases, most of which were minor and controlled by conservative management. Although limited data were available on comprehensive functional assessment, some studies showed that respiratory symptoms, pulmonary function tests, and performance status were significantly improved.

Conclusions: Endoscopic cryotherapy was found to be a safe and useful procedure in the management of endobronchial tumors although its efficacy and appropriate indications have yet to be determined in well-designed controlled studies.

(Korean J Intern Med 2011;26:137-144 )

Keywords: Cryotherapy; Bronchoscopy; Lung neoplasms; Carcinoma, bronchogenic; Airway obstruction

\section{INTRODUCTION}

Despite recent development of therapies and anti-cancer drugs, lung cancer does not yet respond well to treatments and continues to have a poor prognosis. Accordingly, it is ranked first in the world in terms of mortality among malignant tumors [1-3].

Two-thirds of all lung cancers are already in a stage where surgery is difficult by the time of diagnosis, and conservative treatments play an important role. In approximately $30 \%$ of lung cancer patients, central airway obstruction is accompanied by symptoms such as dyspnea and hemoptysis. Local treatment for these symptoms plays an important role in alleviating patient symptoms and improving their quality of life [4]. In progressive lung cancers, accompanied by central airway obstruction, various interventional methods for improving airway obstruction have been tried, including Nd:YAG laser

Received: January 12, 2011

Revised : March 2, 2011

Accepted: March 7, 2011

Correspondence to Kwang-Joo Park, M.D

Department of Pulmonary and Critical Care Medicine, Ajou University School of Medicine, San 5 Woncheon-dong, Yeongtong-gu, Suwon 443-749, Korea

Tel: 82-31-219-5121, Fax: 82-31-219-5124, E-mail: parkkj@ajou.ac.kr 
therapy, electrocautery, brachytherapy, photodynamic therapy and cryotherapy $[4,5]$. Nd:YAG laser therapy, which has been widely used, and electrocauterization are effective and instantly open up the airway, but are more likely to result in such complications as airway perforation [5]. Also, photodynamic therapy is effective on small tumors, but is expensive, and may result in complications, including hemorrhage or secondary skin burns [5-7].

Cryotherapy uses flexible or rigid bronchoscopy to quickly freeze cells to $-70^{\circ} \mathrm{C}$, destroying them. Although it has a relatively long history, it has been used less than other treatment methods $[5,8]$. This is believed to be attributed to the fact that its effect is more delayed and its indication narrower than the more popular Nd:YAG laser therapy. Several case studies have shown that endoscopic cryotherapy is fairly effective and safe, but its objective efficacy has not been proven through largescale controlled studies $[9,10]$. However, based on available research reports, endoscopic cryotherapy has a number of advantages: it is less expensive, and less likely to result in complications, such as perforation or hemorrhage. If it is used for appropriate indications, it is expected to establish itself as a useful interventional treatment method.

In this study, we systematically analyzed and evaluated research data on endoscopic cryotherapy, and discuss reference materials useful in the treatment of airway obstruction caused by tumors.

\section{METHODS}

\section{Literature search strategy}

The strategy to review the literature for 'endoscopic cryotherapy performed on lung and bronchial tumors' focused on studies that used the bronchoscope, and included studies that conducted a comparative analysis of laser therapy, electrocauterization, brachytherapy, stent insertion, and photodynamic therapy. After analysis, operation-related factors, such as safety, response, relapse, survival, and patient condition improvement factors, such as symptom improvement, pulmonary function, performance, quality of life, degree of bronchial obstruction, and oxygen saturation, were selected as major results.

Regarding 'endoscopic cryotherapy for lung and bronchial tumors,' eight domestic databases including KoreaMed and foreign databases like Ovid-Medline, EMBASE, CINAHL, and the Cochrane Library were used. The search strategy integrated 'lung neoplasm, bronchogenic carcinoma, bronchial neoplasm and tracheal neoplasia' and 'cryotherapy, cryosurgery, cryoablation, cryocoagulation, cryodestruction and cryoextraction.' In total, 664 documents in Korean and English were identified initially. Publications that were review articles, editorials, non-human experiments, preclinical studies, and documents containing abstracts only were excluded. In total, 648 documents, including 210 overlapping documents, were excluded, leaving 16 documents in the final evaluation. Each step, from literature review through application of selection criteria to data extraction, was carried out independently by a subcommittee and two evaluators. Scottish Intercollegiate Guidelines Network (SIGN) methodology was used to evaluate the quality of the literature, and levels of evidence and grades of recommendation were selected accordingly [11].

\section{Study inclusion criteria}

- Studies on lung and bronchial tumor patients.

- Studies on cryotherapy using bronchoscopy.

- Studies in which more than one appropriate medical outcome was reported.

\section{Study exclusion criteria}

- Non-human and pre-clinical studies.

- Studies that were not original articles (non-systematic reviews, editorials, letters, opinion pieces).

- Studies not published in Korean or English.

- Cases where the effects of other therapies were mixed with that of cryotherapy.

- Studies that published abstracts only.

\section{Effectiveness assessment of cryotherapy}

The effectiveness of endoscopic cryotherapy for lung and bronchial tumors was evaluated on the basis of discussions of the subcommittee in terms of operationrelated factors and influences on the results of medical treatment. Operation-related factors included response, relapse, survival, and success rate, whereas influences on the results of medical treatment included improvement in clinical symptoms, pulmonary function, performance, quality of life, degree of bronchial obstruction, and the increase in oxygen saturation.

\section{RESULTS}

\section{Literature search results}

In total, one domestic report and 15 foreign reports were 
Table 1. General characteristics of studies selected for evaluation

\begin{tabular}{|c|c|c|c|c|c|c|}
\hline $\begin{array}{l}\text { Serial } \\
\text { no. }\end{array}$ & Year & Author & $\begin{array}{l}\text { No. of } \\
\text { patients }\end{array}$ & $\begin{array}{l}\text { Age (mean } \\
\text { or range) }\end{array}$ & Population & Study type \\
\hline 1 & 2008 & Jung et al. [13] & 4 & $40-64$ & Advanced lung cancer: stage IIIb, 1; stage IV, 3 & Case study \\
\hline 2 & 2007 & Beeson [14] & 645 & 68.3 & $\begin{array}{l}\text { Inoperable lung cancer due to advanced stage, poor } \\
\text { lung function or poor performance status }\end{array}$ & Case study \\
\hline 3 & 2006 & Berotoletti et al. [15] & 18 & 47 & Typical carcinoid tumor & Case study \\
\hline 4 & 2006 & Zoganas et al. [12] & 163 & 67.9 & $\begin{array}{l}\text { Inoperable lung cancer due to advanced stage or } \\
\text { poor general conditions }\end{array}$ & $\begin{array}{l}\text { Comparison } \\
\text { observation }\end{array}$ \\
\hline 5 & 2005 & Asimakopoulos et al. [9] & 329 & 68 & $\begin{array}{l}\text { Inoperable lung cancer due to advanced stage, } \\
\text { poor lung function or poor performance status }\end{array}$ & Case study \\
\hline 6 & 2004 & Hetzel et al. [16] & 60 & $19-81$ & $\begin{array}{l}\text { Endobronchial tumors: lung cancer; } 56 \text {, benign } \\
\text { tumors, 3; malignant lymphoma } 1\end{array}$ & Case study \\
\hline 7 & 2004 & Maiwand et al. [17] & 521 & 67.9 & $\begin{array}{l}\text { Inoperable lung cancer due to advanced stage or } \\
\text { patients' general conditions }\end{array}$ & Case study \\
\hline 8 & 2001 & Deygas et al. [18] & 35 & 61 & $\begin{array}{l}\text { Early superficial bronchogenic carcinoma that } \\
\text { cannot be operated due to comorbidities }\end{array}$ & Case study \\
\hline 9 & 2001 & Noppen et al. [19] & 15 & 63.5 & $\begin{array}{l}\text { Advanced lung cancer, 9; lung carcinoma in situ, 4; } \\
\text { hemangioma, 1; melanoma, } 1\end{array}$ & Case study \\
\hline 10 & 1999 & Maiwand [10] & 153 & 68.8 & $\begin{array}{l}\text { Inoperable lung cancer due to advanced stage, } \\
\text { site of the tumor, poor lung function or poor general } \\
\text { health }\end{array}$ & Case study \\
\hline 11 & 1996 & Mathur et al. [20] & 20 & 62 & $\begin{array}{l}\text { Inoperable endobronchial tumors: primary lung } \\
\text { cancer, } 17 \text {; metastatic lung cancer, } 3\end{array}$ & Case study \\
\hline 12 & 1993 & Marasso et al. [21] & 234 & 62 & $\begin{array}{l}\text { Lung tumors of various status: malignant tumors, } \\
\text { 190; benign tumors, } 44\end{array}$ & Case study \\
\hline 13 & 1990 & Walsh et al. [22] & 33 & 75 & $\begin{array}{l}\text { Inoperable lung cancer due to advanced stage or } \\
\text { poor general conditions }\end{array}$ & Case study \\
\hline 14 & 1986 & Homasson et al. [23] & 22 & $39-88$ & $\begin{array}{l}\text { Inoperable lung cancer due to advanced stage or } \\
\text { poor general conditions }\end{array}$ & Case study \\
\hline 15 & 1986 & Maiwand [24] & 75 & 63 & $\begin{array}{l}\text { Advanced lung cancer: previous surgery, } 26 \text {; } \\
\text { previous radiotherapy, 16; cryotherapy as primary } \\
\text { therapy, } 33\end{array}$ & Case study \\
\hline 16 & 1981 & Sanderson et al. [25] & 28 & 63 & $\begin{array}{l}\text { Inoperable lung cancer due to advanced stage or } \\
\text { poor general conditions }\end{array}$ & Case study \\
\hline
\end{tabular}

used for the evaluation. The safety and effectiveness of endoscopic cryotherapy for the lung and bronchus were discussed in all 16 documents. Of the 16 selected reports, one was a comparison observation study with evidence level 2 [12], and the remaining 15 were case studies [9,10,13-25]. General characteristics of the studies are presented in Table 1.

\section{Clinical data and outcomes}

\section{Safety}

The safety of endoscopic cryotherapy for lung and bronchial tumors was evaluated on the basis of one comparison observation study, and 15 case studies with regard to deaths and complications within 30 days. Except for the small-scale study involving four subjects, complications, such as hemorrhage, mediastinal emphysema, atrial fibrillation, and dyspnea, occurred 
Table 2. Complications of endoscopic cryotherapy

\begin{tabular}{llcll}
\hline Year & \multicolumn{1}{c}{ Author } & Occurrence & \multicolumn{1}{c}{ Complications } & Treatment \\
\hline 2008 & Jung et al. [13] & $2 / 4$ & Mediastinal emphysema, hemoptysis & Controlled by conservative management \\
2007 & Beeson [14] & & Hemorrhage & Controlled by conservative management \\
2006 & Berotoletti et al. [15] & $2 / 18$ & Hemorrhage, subcutaneous emphysema & Controlled by conservative management \\
2005 & Asimakopoulos et al. [9] & $35 / 329$ & Hemorrhage, atrial fibrillation, dyspnea & Controlled by conservative management \\
2004 & Hetzel et al. [16] & $10 / 60$ & Hemorrhage & Controlled by hemostasis with plasma \\
& & & & beamer \\
2004 & Maiwand et al. [17] & $49 / 521$ & Hemoptysis, atrial fibrillation, dyspnea & Transient and not serious complications \\
2001 & Deygas et al. [18] & $0 / 35$ & & \\
2001 & Noppen et al. [19] & $0 / 12$ & & Controlled by conservative management \\
1999 & Maiwand [10] & $11 / 153$ & Hemorrhage, pneumothorax, anesthesia & \\
& & & complication & \\
1990 & Walsh et al. [22] & $0 / 33$ & & Transient \\
1986 & Homasson et al. [23] & $2 / 27$ & Light fever & \\
1986 & Maiwand [24] & $0 / 75$ & &
\end{tabular}

Table 3. 30-day mortality after endoscopic cryotherapy

\begin{tabular}{llc}
\hline Year & \multicolumn{1}{c}{ Author } & Occurrence (\%) \\
\hline 2005 & Asimakopoulos et al. [9] & $9 / 32(2.4)$ \\
2004 & Maiwand et al. [17] & $7 / 512(1.2)$ \\
1999 & Maiwand [10] & $0 / 153(0.0)$ \\
1986 & Homasson et al. [23] & $1 / 27(3.7)$ \\
1981 & Sanderson et al. [25] & $2 / 28(7.1)$ \\
\hline
\end{tabular}

in $11.1 \%$ of all cases in 10 of the 16 studies. Most of the complications were controlled with simple conservative treatments (Table 2). In five of the 16 studies, mortality occurred in $7.1 \%$ of cases within 30 days of the operation. Causes of death were hemoptysis and respiratory failure. However, it was considered that most of the mortality was more likely to be associated with disease progression rather than a direct consequence of the procedures (Table 3).

\section{Response rate}

The case study by Hetzel et al. [16] evaluated the response rate of endobronchial tumors accompanied by a high level of stenosis after cryotherapy; the complete response rate was $61 \%(37 / 60)$, the partial response rate was $22 \%(13 / 60)$, and the total response rate was $83 \%$. Deygas et al. [18] performed cryotherapy in treating 35 early superficial bronchogenic carcinoma patients who were inoperable due to comorbidities. The process was repeated 10-15 days later. They also followed 22 of the 35 patients; as a result, the complete response rate after 1 year was 91\% (32/35). Homasson et al. [23] performed three cycles of $-80^{\circ} \mathrm{C}$ cryotherapy in 27 lung cancers including patients who underwent preoperative radiation treatment $(n=5)$, chemotherapy ( $n=3)$, and chemoradiation therapy $(n=3)$. The procedure was repeated 4-6 days layer and the response rate was evaluated. The results showed that the response rate of malignant tumors was $61.9 \%$ (13/21), and that of benign tumors was $100 \%(5 / 5)$. In the case study by Jung et al. [13], endoscopic cryotherapy was performed on one stage IIIb, and three stage IV lung cancer patients, with a success rate of $75 \%(3 / 4)$. Noppen et al. [19] performed $3 \times 20$-s cycles of $-80^{\circ} \mathrm{C}$ cryotherapy in five invasive lung cancer patients, four carcinoma in situ (CIS) patients, two metastatic cancer patients, and one hemangioma patient. The process was repeated 1-2 weeks later, and the success rate was evaluated. Results showed the success rate to be $80 \%(4 / 5)$ in lung cancer, and zero in metastatic lung cancer. In all cases where the operation needed to be repeated, the second operation was a success. In the case study by Beeson $[14]-70^{\circ} \mathrm{C}$ cryotherapy was performed on 645 patients who were inoperable for various reasons. They reported that the tumor in the bronchus was reduced, and the airway was opened in most cases. Walsh et al. [22] performed three cycles of $-70^{\circ} \mathrm{C}$ cryotherapy for 33 inoperable patients, and evaluated the degree of bronchial obstruction. The degree of bronchial 
obstruction improved in $77 \%$ (20/26) of the patients, and, radiologically, atelectasis improved in $24 \%(7 / 24)$ of the patients.

\section{Relapse rate}

Hetzel et al. [16] reported a relapse rate of $24.6 \%$ (14/57) 10-24 weeks after cryotherapy in endobronchial tumors with obstruction. Deygas et al. [18] performed two successive sessions of cryotherapy for 35 superficial endobronchial tumors, and the relapse rate was $28 \%$ (10/35) after 13-45 months. According to the case study by Berotoletti et al. [15], three cycles of $-70^{\circ} \mathrm{C}$ cryotherapy was performed for 18 typical carcinoid tumor patients. They were followed up for 44.5 months, and there was no relapse. However, after 7 years, two of the patients had relapsed (11.1\%).

\section{Survival rate}

In the case study by Beeson [14], $-70^{\circ} \mathrm{C}$ cryotherapy was performed on 645 patients who were inoperable. Among them, squamous cell carcinoma patients accounted for $68.3 \%$, adenocarcinoma $15.2 \%$, large cell carcinoma $2.6 \%$, undifferentiated carcinoma $5.2 \%$, and small cell carcinoma $8.7 \%$. Patients in stage II accounted for $6.7 \%$, stage IIIa 21.0\%, IIIb $23.9 \%$, and stage IV $48.4 \%$. This case study did not present comprehensive data on survival rates, but suggested the possibility of an increase in the survival rate due to the procedure. In the case study by Zoganas et al. [12], cryotherapy was performed for inoperable cancer patients, and the survival rate was analyzed 2 years later. The result showed that the survival rate was $19.3 \%$ in the group to which only cryotherapy was performed, and $25 \%$ in the group to which anticancer treatment was performed concurrently, but the difference was not statistically significant ( $p=0.388$ ).

In the case study by Asimakopoulos et al. [9], cryotherapy was performed more than twice for advanced lung cancer patients. This group survived for 15 months, on average, whereas the other group for whom cryotherapy was performed only once survived for 8.3 months, on average. In the case study by Hetzel et al. [16], cryotherapy was performed on patients with protruding tumors accompanied with a high level of stenosis, and their survival rate after 36 weeks was 52.6\% (30/57). Maiwand and Asimakopoulos [17] performed two sessions of cryotherapy for 521 cancer patients who were inoperable, and observed them for 18 months (4 to 84 months). Average survival was 8.2 months, and according to the stage, the average survival period of the patients was 15.1 months in stage IIb, 8.5 months in stage IIIa, 9.0 months in stage IIIb, and 6.6 months in stage IV. Also, the 1-year survival rate was $38.4 \%$, while the 2-year survival rate was $15.9 \%$. Deygas et al. [18] followed up 22 of 35 early superficial cancer patients, and the 2-year survival rate was $62.5 \%$ (20/32), and after $48-89$ months the survival rate was $50 \%(11 / 22)$. Six of the 19 died from other causes, six died of a relapse in the same location, and the remaining seven died of metastasis in other locations. Maiwand [24] performed two cycles of $-70^{\circ} \mathrm{C}$ cryotherapy on 75 lung cancer patients with endobronchial tumors, who had undergone pneumonectomy $(\mathrm{n}=18)$, preoperative radiation treatment $(\mathrm{n}=16)$, and pneumonectomy and radiation treatment $(n=8)$, repeated for 2,4 , and 8 weeks, and followed them for 12 months. Results showed that the survival period of 19 patients was less than 1 month, 35 patients survived for 1-5 months, six patients survived for 6-11 months, and the remaining 16 patients survived for 12 months or longer.

Improvement in clinical symptoms and pulmonary function

In most studies, the procedure was performed for advanced lung and bronchial cancer patients who were inoperable. Following the procedure, symptoms, such as dyspnea, cough, hemoptysis, and stridor, showed statistically significant improvements. This was also the case for pulmonary function; forced expiratory volume at 1 second $\left(\mathrm{FEV}_{1}\right)$, forced vital capacity (FVC), and maximal flow rates showed statistically significant improvements after cryotherapy. The results of the studies are summarized in Table 4. Walsh et al. [22] reported that oxygen saturation $\left(\mathrm{SaO}_{2}\right)$ improved in $77 \%(20 / 26)$ of patients.

\section{Improvement in performance and quality of life}

In the study by Maiwand and Asimakopoulos [17], performance status and quality of life were assessed before and after cryotherapy in 521 inoperable cancer patients. Results showed that the Karnofsky score improved significantly, from 60 to 75 , and the WHO score was reduced significantly, from 3.04 to 2.20. Walsh et al. [22] reported that in 33 inoperable patients, the performance of $27 \%(6 / 22)$ improved in the 6-minutes walking test. In the case study by Asimakopoulos et al. [9], cryotherapy was performed twice or more for Group A of advanced cancer patients, and once for Group B. The Karnofsky scores of 
Table 4. Improvement in clinical symptoms and pulmonary function

\begin{tabular}{|c|c|c|c|c|}
\hline Year & Author & Operation method & Improvement of clinical symptoms & $\begin{array}{l}\text { Improvement of the pulmonary } \\
\text { function }\end{array}$ \\
\hline 2008 & Jung et al. [13] & $\begin{array}{l}-89^{\circ} \mathrm{C} \text { freezing for } \\
5-20 \mathrm{sec} \text {, and thawing } \\
\text { repeated }\end{array}$ & $\begin{array}{l}\text { Cases } 1 \text { and 2: dyspnea and } \\
\text { atelectasis improved; Case 3: } \\
\text { dyspnea improved }\end{array}$ & Not mentioned \\
\hline 2007 & Beeson [14] & $-70^{\circ} \mathrm{C}$ & & $\mathrm{FEV}_{1}$ and $\mathrm{FVC}$ improved \\
\hline 2006 & Zoganas et al. [12] & Not mentioned & Single: $65 \%$; Concurrent ${ }^{\mathrm{a}}: 80 \%$ & Not mentioned \\
\hline 2005 & $\begin{array}{l}\text { Asimakopoulos et al. } \\
\text { [9] }\end{array}$ & $\begin{array}{l}\text { 3-min, }-70^{\circ} \mathrm{C} \\
2 \text { times or more (Group } \\
\text { A), once (Group B) }\end{array}$ & $\begin{array}{l}\text { Dyspnea improvement rate: Group A, } \\
36.6 \% \text {; Group B, } 10.8 \% \\
\text { Coughing improvement rate: Group A, } \\
41.9 \% \text {; Group B, } 11.4 \% \\
\text { Hemoptysis improvement rate: Group } \\
\text { A, } 35 \% \text {; Group B, } 6 \%\end{array}$ & $\begin{array}{l}\text { Group A: significant } \\
\text { improvement of FVC } \\
\text { Group B: no significant } \\
\text { improvement of FVC or FEV } 1\end{array}$ \\
\hline 2004 & Maiwand et al. [17] & $\begin{array}{l}3-\mathrm{min},-70^{\circ} \mathrm{C} \\
2.4 \text { times on average, } \\
\text { repeated } 2 \mathrm{wk} \text { later }\end{array}$ & $\begin{array}{l}\text { Cough, } 69 \% \text {; dyspnea, } 59.2 \% \text {; } \\
\text { hemoptysis, } 76.4 \% \text {; chest pain, } 42 \%\end{array}$ & $\begin{array}{l}\text { Significant improvement of } \\
\operatorname{FEV}_{1}(1.39 \rightarrow 1.51 \mathrm{~L}) \text { and } \\
\text { FVC }(1.93 \rightarrow 2.13 \mathrm{~L})\end{array}$ \\
\hline 1990 & Walsh et al. [22] & $\begin{array}{l}3-\min ,-70^{\circ} \mathrm{C} \\
3 \text { times, repeated } 2-4 \\
\text { wk later }\end{array}$ & $\begin{array}{l}\text { Subjective improvement, 23/33 } \\
\text { (70\%); dyspnea score, 10/27 (37\%); } \\
\text { hemoptysis, 6/9 (67\%); stridor, } 4 / 7 \\
(56 \%)\end{array}$ & $\begin{array}{l}\text { Improvement rates: } \text { FEV }_{1}, 7 / 29 \\
(24 \%) ; \text { FVC, } 7 / 29(24 \%) ; \\
\text { MEF, 6/29 (21\%); } \\
\text { MIF, 3/11 (27\%) }\end{array}$ \\
\hline 1986 & Homasson et al. [23] & $\begin{array}{l}\text { 1-min, }-80^{\circ} \mathrm{C} \\
3 \text { times, repeated } 4-6 \\
\text { days later }\end{array}$ & $\begin{array}{l}\text { Favorable, 17: atelectasis improved } \\
(15), \text { hemoptysis improved (2); } \\
\text { no benefit, 9: technical failure (5), no } \\
\text { reaction (3), death before treatment (1) }\end{array}$ & Not mentioned \\
\hline 1986 & Maiwand [24] & $\begin{array}{l}150 \mathrm{sec},-70^{\circ} \mathrm{C} \\
2 \text { times, repeated } 2,4, \\
\text { and } 8 \text { wk later }\end{array}$ & $\begin{array}{l}\text { Symptom improvement: stridor, 20/33 } \\
\text { (61\%); dyspnea, } 23 / 31(74 \%) ; \\
\text { hemoptysis, } 11 / 11(100 \%)\end{array}$ & Not mentioned \\
\hline 1981 & Sanderson et al. [25] & $\begin{array}{l}2-\min ,-160^{\circ} \mathrm{C} \\
3 \text { times, performed } 1-8 \\
\text { times }\end{array}$ & $\begin{array}{l}\text { Favorable, } 15 / 28(53.6 \%) \text { : tumors } \\
\text { reduced }(8) \text {, hemorrhage reduced }(4) \text {, } \\
\text { airway opened (3); no benefit, } 13 / 28 \\
(46.4 \%)\end{array}$ & Not mentioned \\
\hline
\end{tabular}

$\mathrm{FEV}_{1}$, forced expiratory volume at $1 \mathrm{sec}$; FVC, forced vital capacity; MEF, maximal expiratory flow rate; MIF, maximal inspiratory flow rate.

${ }^{a}$ Concurrent treatment: concurrent with radiotherapy, brachytherapy or chemotherapy.

Group A were 67.7, 72.2, and 74.6 before cryotherapy, after the first cryotherapy and after the second cryotherapy, respectively, whereas the Karnofsky scores in Group B was 67.5, 74.6, and 73.6, respectively. Both groups showed statistically significant improvements.

\section{DISCUSSION}

We have discussed the available safety and efficacy data of cryotherapy in the treatment of the endobronchial tumors, although detailed and comprehensive analysis was not possible due to the variability of methodologies and lack of standardization of the procedures. According to this study, endoscopic cryotherapy generally showed high treatment efficiency in approximately $80 \%$ of cases, although there was variation depending on operation methods or target patient groups. It was also effective in improving quality of life, improving symptoms, like dyspnea, and improving pulmonary function. In lung tumors, airway obstruction is one of the symptoms seen in patients, but it has an important influence on quality of life, so appropriate treatment is required on many occasions, and although it may be difficult to expect that 
such local treatment will ultimately improve the survival rate, it will play an important role in patient management and conservative treatment. Laser therapy has been the preferred treatment for airway obstruction due to tumors. This is perhaps because laser therapy can instantly and powerfully open up even severe obstructions [26-28]. Laser therapy is known to result in more complications, including hemorrhage and perforation. Cryotherapy can be said to be superior in terms of safety [5]. Photodynamic therapy is also a useful local treatment method for various purposes, including curative treatment of an early cancer in the airway or alleviation of airway obstruction, but it is relatively expensive, and pre-and post-operation management is cumbersome [29]. Other endobronchial local treatment methods, including brachytherapy and electric cauterization, are used, and these methods have their own strengths and weaknesses. Accordingly, several factors, such as the status of the patient's disease, experience of the practitioner, and financial considerations, must be taken into account when any of these methods are selected.

As described previously, endoscopic cryotherapy may still be less researched and used than other treatment methods, including laser therapy. Because cryotherapy does not affect the cartilage or collagen in the bronchus, there is almost no risk of perforation, and, in this sense, it is safer than other methods, but it has less destructive power and its effect is delayed. Thus, its efficacy may be considered to be limited in cases with severe airway obstruction due to a large and extensive tumor [5]. As the spectrum of cryotherapy is about $5 \mathrm{~mm}$, it is limited, and though it is possible to overcome this with repetition, there are other limitations. As laser therapy is more effective in opening up severe obstructions, it may be inappropriate to select cryotherapy as an initial treatment in such a case. It is recommended to perform laser therapy or cauterization first, and then cryotherapy as an additional treatment for the remaining tumor. It can also be a useful treatment method in removing early tumors limited to the airway [5]. As reports on the supplementary efficacy and synergistic effect of using cryotherapy together with anticancer chemotherapy or radiation treatment are published, the possibility of using it as part of concurrent treatments is also suggested [30,31].

Limitations of the analysis in this study relate to cryotherapy not being standardized; individual studies differed in research methods and frequencies, and the characteristics of patient groups varied. Thus, comprehensive statistical analysis was difficult. Accordingly, comprehensive statistical analysis was avoided in the results section, and we focused on describing the characteristics and results of each study. Additionally, both rigid and flexible bronchoscopy can be used for cryotherapy; depending on the choice, efficacy can vary. Because there are many different types of probe, there are slight differences in the mechanism of action and efficacy. Thus, there are limitations in comprehensively analyzing multiple studies [5].

In conclusion, endoscopic cryotherapy performed for endobronchial tumors is a safe and effective treatment method that will improve the symptoms, pulmonary function, and performance in patients with endobronchial obstruction, especially in inoperable cases. Given the lack of well-designed studies comparing it with other treatment methods, it must be objectively compared with other treatment methods and more cases need to be analyzed in future studies.

\section{Conflict of interest}

No potential conflict of interest relevant to this article was reported.

\section{Acknowledgments}

This study was supported by 2008 grant from the Ministry for Health, Welfare and Family Affairs' research fund.

\section{REFERENCES}

1. Parkin DM. Global cancer statistics in the year 2000. Lancet Oncol 2001;2:533-543.

2. Montazeri A, Gillis CR, McEwen J. Quality of life in patients with lung cancer: a review of literature from 1970 to 1995. Chest 1998;113:467-481.

3. Hong J, Kyung SY, Lee SP, et al. Pemetrexed versus gefitinib versus erlotinib in previously treated patients with non-small cell lung cancer. Korean J Intern Med 2010;25:294-300.

4. Hetzel MR, Smith SG. Endoscopic palliation of tracheobronchial malignancies. Thorax 1991;46:325-333.

5. Vergnon JM, Huber RM, Moghissi K. Place of cryotherapy, brachytherapy and photodynamic therapy in therapeutic bronchoscopy of lung cancers. Eur Respir J 2006;28:200-218.

6. Kvale PA, Selecky PA, Prakash UB; American College of Chest Physicians. Palliative care in lung cancer: ACCP evidence-based clinical practice guidelines (2nd edition). Chest 2007;132(3 
Suppl):368S-403S.

7. Jang TW, Kim HK, Oak CH, Jung MH. Photodynamic therapy in early lung cancer: a report of two cases. Korean J Intern Med 2006;21:178-182.

8. Sanderson DR, Neel HB, Payne WS, Woolner LB. Cryotherapy for bronchogenic carcinoma: report of a case. Mayo Clin Proc 1975;50:435-437.

9. Asimakopoulos G, Beeson J, Evans J, Maiwand MO. Cryosurgery for malignant endobronchial tumors: analysis of outcome. Chest 2005;127:2007-2014.

10. Maiwand MO. The role of cryosurgery in palliation of tracheobronchial carcinoma. Eur J Cardiothorac Surg 1999;15:764-768.

11. Lowe G, Twaddle S. The Scottish Intercollegiate Guidelines Network (SIGN): an update. Scott Med J 2005;50:51-52.

12. Zoganas L, Bablekos G, Maiwand M, et al. Quality of life survery and palliative care in lung cancer patients. Hippokratia 2006;10:163-166.

13. Jung JY, Lee SY, Kim DH, et al. Clinical benefits and complications of cryotherapy in advanced lung cancer with central airway obstruction. Tuberc Respir Dis 2008;64:272-277.

14. Beeson J. Palliation of tracheobronchial carcinoma: the role of cryosurgery. J Perioper Pract 2007;17:332, 334-336, 338-339.

15. Bertoletti L, Elleuch R, Kaczmarek D, Jean-Francois R, Vergnon JM. Bronchoscopic cryotherapy treatment of isolated endoluminal typical carcinoid tumor. Chest 2006;130:1405-1411.

16. Hetzel M, Hetzel J, Schumann C, Marx N, Babiak A. Cryorecanalization: a new approach for the immediate management of acute airway obstruction. J Thorac Cardiovasc Surg 2004;127:1427-1431.

17. Maiwand MO, Asimakopoulos G. Cryosurgery for lung cancer: clinical results and technical aspects. Technol Cancer Res Treat 2004;3:143-150.

18. Deygas N, Froudarakis M, Ozenne G, Vergnon JM. Cryotherapy in early superficial bronchogenic carcinoma. Chest 2001;120:2631.

19. Noppen M, Meysman M, Van Herreweghe R, Lamote J, D’Haese J, Vincken W. Bronchoscopic cryotherapy: preliminary experience. Acta Clin Belg 2001;56:73-77.
20. Mathur PN, Wolf KM, Busk MF, Briete WM, Datzman M. Fiberoptic bronchoscopic cryotherapy in the management of tracheobronchial obstruction. Chest 1996;110:718-723.

21. Marasso A, Gallo E, Massaglia GM, Onoscuri M, Bernardi V. Cryosurgery in bronchoscopic treatment of tracheobronchial stenosis: indications, limits, personal experience. Chest 1993;103:472-474.

22. Walsh DA, Maiwand MO, Nath AR, Lockwood P, Lloyd MH, Saab M. Bronchoscopic cryotherapy for advanced bronchial carcinoma. Thorax 1990;45:509-513.

23. Homasson JP, Renault P, Angebault M, Bonniot JP, Bell NJ. Bronchoscopic cryotherapy for airway strictures caused by tumors. Chest 1986;90:159-164.

24. Maiwand MO. Cryotherapy for advanced carcinoma of the trachea and bronchi. Br Med J (Clin Res Ed) 1986;293:181-182.

25. Sanderson DR, Neel HB, Fontana RS. Bronchoscopic cryotherapy. Ann Otol Rhinol Laryngol 1981;90:354-358.

26. Brutinel WM, Cortese DA, Edell ES, McDougall JC, Prakash UB. Complications of Nd:YAG laser therapy. Chest 1988;94:902-903.

27. Brutinel WM, Cortese DA, McDougall JC, Gillio RG, Bergstralh EJ. A two-year experience with the neodymium-YAG laser in endobronchial obstruction. Chest 1987;91:159-165.

28. Desai SJ, Mehta AC, VanderBrug Medendorp S, Golish JA, Ahmad M. Survival experience following Nd:YAG laser photoresection for primary bronchogenic carcinoma. Chest 1988;94:939-944.

29. Maziak DE, Markman BR, MacKay JA, Evans WK. Photodynamic therapy in nonsmall cell lung cancer: a systematic review. Ann Thorac Surg 2004;77:1484-1491.

30. Forest V, Peoc'h M, Campos L, Guyotat D, Vergnon JM. Effects of cryotherapy or chemotherapy on apoptosis in a non-smallcell lung cancer xenografted into SCID mice. Cryobiology 2005;50:29-37.

31. Vergnon JM, Schmitt T, Alamartine E, Barthelemy JC, Fournel $\mathrm{P}$, Emonot A. Initial combined cryotherapy and irradiation for unresectable non-small cell lung cancer: preliminary results. Chest 1992;102:1436-1440. 